\title{
FITOTERAPIA BRASILEIRA: ANÁLISE DOS EFEITOS BIOLÓGICOS DA SUCUPIRA (BOWDICHIA VIRGILIOIDES E PTERODON EMARGINATUS)
}

\author{
Marcelle Souza Lima Machado1; Karen Aparecida Bruno2; Mayara de Oliveira Melo; \\ Marcia Kiyomi Koike ${ }^{3}$. \\ 1Programa de Pós-Graduação em Ciências da Saúde, Instituto de Assistência Médica do Servidor Público Esta- \\ dual (IAMSPE), São Paulo, Brasil; ${ }^{2}$ Curso de Naturologia, Escola de Ciências da Saúde, Universidade Anhembi \\ Morumbi, São Paulo, Brasil; ${ }^{3}$ Disciplina de Emergências Clínicas, Departamento de Clínica Médica, Faculdade \\ de Medicina da Universidade de São Paulo, São Paulo, Brasil. Autor correspondente: Profa. Dra. Marcia Koike: \\ E-mail: mkoike2011@gmail.com
}

\section{Resumo}

A Sucupira é uma planta nativa utilizada como medicamentos nas tradições populares para a cura de feridas, para o tratamento de diabetes, de reumatismo, de artrite, de doenças de pele, de faringites, de amidalites, de bronquites e para dores na coluna. A Sucupira é comumente utilizada em garrafadas, como componente de energéticos, juntamente com plantas como catuaba e muirapuama. Apesar de muitas plantas serem utilizadas comumente no tratamento e prevenção de diversas doenças, não há garantia da segurança e eficácia para a grande maioria dos produtos comercializados produzidos a partir destas plantas que estão sendo utilizados por grande parte da população. O presente artigo teve o objetivo de identificar as evidências científicas sobre as propriedades químicas presentes na composição de duas espécies de sucupira, a Pterodon emarginatus e a Bowdichia virgilioides, popularmente mais conhecidas como sucupira branca e sucupira preta, respectivamente, e relacioná-las com os seus efeitos biológicos relatados na medicina popular. Para assim fazer com que Naturólogos e outros profissionais da área da saúde tenham maior segurança e eficácia quando forem indicar a sucupira. Foi realizada uma pesquisa baseada nos Princípios da Revisão Sistemática, sobre os efeitos biológicos de duas espécies distintas de sucupira. Os artigos científicos mostraram que P. emarginatus possui ação: antimicrobiana, leishmanicida e antinoceptiva e a B. virgilioides possui ação: antiinflamatória, antimicrobiana, ansiolítica, hipoglicemiante e cicatricial. Estes resultados estão de acordo com o que foi encontrado na bibliografia sobre a indicação terapêutica da sucupira na medicina popular, como dores de garganta, bronquite, reumatismo, artrite, feridas e diabetes.

Palavras chave: Sucupira, Sucupira Preta, Sucupira Branca, Bowdichia sp., Pterodon sp., Plantas medicinais, Fitoterapia.

\section{Introdução}

A Sucupira é o nome popular de diversos tipos de Fabaceae, sendo as duas espécies mais comumente utilizadas na medicina popular, a Sucupira Branca (Pterodon emarginatus) e a Sucupira Preta (Bowdichia virgilioides).
A Sucupira Branca (P. emarginatus) é uma árvore aromática nativa que ocorre frequentemente no cerrado brasileiro e na sua transição para a floresta semidecídua, encontrada nos Estados de Goiás, Mato Grosso do Sul, Minas Gerais e São Paulo, podendo atingir 8-16m de altura ${ }^{1}$.

A Sucupira Preta (B. virgilioides) é uma árvo- 


\section{Brazilian Journal of Natural Sciences | Versão On-line ISSN 2595 - 0584 \\ Edição no 1- vol. 2 - maio 2018 | www.bjns.com.br}

re grande e ramosa, com ampla distribuição geográfica ocorrendo desde o Estado do Pará até São Paulo, empregada no paisagismo em geral e para fornecimento de madeira ${ }^{2}$.

Na medicina popular, a Sucupira é comumente utilizada em garrafadas, como componente de energéticos, juntamente com plantas como catuaba e muirapuama. Extratos alcoólicos dos frutos são utilizados na medicina popular como anti-inflamatório e analgésico. A casca da Sucupira é utilizada na medicina popular para a cura de feridas, como anti-ulcerativo e anti-diabéticos ${ }^{3}$. As sementes são utilizadas no tratamento de reumatismo, artrite e doenças de pele, no tratamento de faringites, amidalites e bronquites ${ }^{4}$.

A visão da Naturologia sobre fitoterápicos busca integrar totalmente o ser humano, o seu ambiente e a sua interação. Embasado na pluralidade de sistemas terapêuticos complexos vitalistas, que parte de uma visão multidimensional do processo de saúde-doença, a Naturologia se utiliza da relação de interagência e de práticas integrativas e complementares para o cuidado e a atenção à saúde.

Neste contexto, o embasamento do conhecimento aprofundado sobre determinada planta visa uma garantia de eficácia mais atingível, ficando evidente a importância de se ter uma base cientifica sólida respeitando os saberes populares na utilização de plantas medicinais. Assim, este trabalho visa identificar as evidências científicas das propriedades químicas presentes na composição das duas espécies de sucupira, a P. emarginatus e a B. virgilioides, e sua relação com os seus efeitos biológicos relatados na medicina popular.

\section{Métodos}

A pesquisa de revisão da literatura foi baseada nos Princípios da Revisão Sistemática ${ }^{5,6}$, sobre os efeitos biológicos de duas espécies distintas de sucupira. Os princípios da revisão que foram utilizados são: definir com precisão a pergunta de pesquisa e as informações necessárias para respondê-la; estabelecer a priori os critérios de inclusão e exclusão dos estudos; utilizar uma metodo- logia explícita e reproduzível; realizar uma busca sistemática e eficiente de estudos primários, para a identificação de todas as pesquisas que podem preencher os critérios de inclusão; selecionar estudos relevantes e metodologicamente adequados por meio de uma análise da validade dos achados; minimizar vieses, através da metodologia sistemática e explícita; apresentar um resumo estruturado, com a síntese das características e dos achados dos estudos incluídos, vantagens e desvantagens; definição clara das conclusões que poderão ser aplicadas na prática.

\section{Procedimento de coleta dos dados}

Data da publicação: Não houve restrição por ano de publicação.

Locais de pesquisa e coleta de dados: PubMed/ MEDLINE, Scielo e ScopMed.

Critério de Inclusão: Artigos que tenham sido publicados em revistas indexadas; incluir um grupo de intervenção e um grupo controle; ser um estudo clínico randomizado ou com animais ou com cultura de células; um $\mathrm{n}>5$ em cada grupo, relatos de caso e artigos em inglês e português. Alguns livros didáticos foram utilizados para consulta sobre a Medicina popular.

Critério de Exclusão: Artigos descritivos; resumos ou comunicações em congressos; estudos sem um grupo controle; dissertações, teses e artigos de revisão.

Para pesquisa foram utilizados os nomes científicos da Sucupira Preta (Bowdichia virgilioides) e da Sucupira Branca (Pterodon emarginatus).

Os artigos pesquisados foram catalogados no Google Forms, ocorrendo, nesta etapa o descarte dos artigos repetidos e fora dos critérios de inclusão. Os dados agrupados em tabela foram separados conforme: base pesquisada, dados referenciais, título, autor, ano, país em que o estudo foi realizado, nome científico da planta, experimento com animais ou células, objeto de estudo, parte utilizada da planta, tipo de extração, substância extraída, objetivo do estudo, protocolo, via de administração, frações ativas, resultado e conclusão. 


\section{Brazilian Journal of Natural Sciences | Versão On-line ISSN 2595 - 0584 \\ Edição no 1- vol. 2 - maio 2018 | www.bjns.com.br}

\section{Resultados}

Foram obtidos quinze artigos científicos sobre a sucupira das espécies B. virgilioides e P. emarginatus, dos quais onze foram utilizados para esta revisão: cinco artigos científicos referentes à B. virgilioides e seis artigos científicos referentes à $\mathrm{P}$. emarginatus. Outros quatro artigos da espécie P. emarginatus foram descartados no critério de inclusão e exclusão, pois dissertavam sobre a germinação, anatomia da semente e variabilidade química do óleo essencial. Os resultados foram apresentados de acordo com a ação relatada:

\section{Atividade antiinflamatória}

Pesquisas em ratos indicaram que o extrato etanólico da casca do caule da B. virgilioides, exerce ação anti-inflamatória via inibição da síntese e secreção de prostaglandinas ${ }^{7}$. Apenas este artigo descreveu o efeito anti-inflamatório da planta.

\section{Atividade antinoceptiva}

Os dados obtidos em estudos de DUTRA et al $(2012)^{8}$ revela que o óxido de etileno obtido a partir das sementes da P. emarginatus apresenta menor citotoxicidade em células normais e maior atividade citotóxica em células cancerosas. E, além disso, revela que o óxido de etileno pode atuar, pelo menos parcialmente, na inibição da morte celular por apoptose.

\section{Atividade cicatricial}

O extrato aquoso da B. virgilioides melhora a cicatrização cutânea em ratos quando utilizado de forma tópica por nove dias. Esta melhora na cicatrização se deve possivelmente devido ao aumento da atividade de fibroblastos?

\section{Atividade antimicrobiana}

De acordo com ALMEIDA et al. $(2006)^{10}$, o óleo inibiu o crescimento de bactérias Micrococcus luteus e de várias cepas de fungos testadas:
Candida albicans, Candida guilliermondii, Candida stellatoidea e Trichophyton rubrum, sendo C. guilliermondii o microrganismo mais sensível.

O estudo feito por BUSTAMANTE et al (2010) ${ }^{11}$ verificou a presença de flavonóides, heterosídeos, saponínicos, resinas e traços de esteróides e triterpenóides no pó da casca da Pterodon emarginatus e concluiu que o extrato etanólico bruto apresentou atividade antimicrobiana contra bactérias Gram -positivas esporuladas: Clostridium sporogenes, Bacillus cereus, Bacillus subtilis, Bacillus stearothermophylus e não esporuladas: Staphylococcus aureus, Rhodococcus equi, Micrococcus luteus e Micrococcus roseus; Gram-negativas: Escherichia coli, Agrobacterium tumefaciens, Salmonella choleraesuis, Salmonella typhymurium, Salmonella sp., Enterobacter aerogenes, Enterobacter cloacae, Serratia marcescens, Pseudomonas aeruginosa e contra o fungo C.albicans.

Em contraste, FERREIRA et al. (2014) ${ }^{12}$ observou que o óleo essencial das sementes P. emarginatus não possui atividade antimicrobiana contra $S$. aureus, P. aeruginosa e E. coli. Os autores sugerem que a amostra das sementes testadas não apresentou as substâncias químicas potencialmente ativas sobre as linhagens analisadas, o que explica a ausência de ação.

\section{Atividade leishmanicida}

O óleo essencial das sementes de Pterodon emarginatus inibiu o crescimento de S.aureus ATCC 25923 e as frações hexânica e butanólica apresentaram expressiva atividade in vitro para L.amazonensis. Estes resultados indicam que moléculas bioativas nas sementes de Pterodon emarginatus podem ser utilizadas como protótipos para o desenvolvimento de novos fármacos e/ou como fonte de matérias-primas farmacêuticas antimicrobianas e leishmanicidas ${ }^{13}$.

\section{Atividade ansiolítica}

Em seu estudo, VIEIRA et al (2013) ${ }^{14}$ afirmaram que a $B$. virgilioides tem efeitos agudo e subcronico similares ao ansiolítico sem comprometer 


\section{Brazilian Journal of Natural Sciences | Versão On-line ISSN 2595 - 0584 \\ Edição no 1- vol. 2 - maio 2018 | www.bjns.com.br}

a atividade motora. Eles demonstram em camundongos tratados com doses de extrato aquoso da casca da Bowdichia virgilioide administradas aguda ou cronicamente apresentam resultados de testes comportamentais próximos aos tratados com diazepam. Os autores acreditam que o extrato aquoso apresenta substancias tais como alcalóides, flavonóides e saponina, que por ação sinérgica atuam com ansiolíticos. Foi a primeira vez que foi relatado o uso do extrato aquoso da Bowdichia virgilioides, com efeito do tipo ansiolítico, e que não afetou a atividade locomotora.

\section{Atividade hipoglicemiante}

O extrato da raiz da B. virgilioides promove um efeito anti-hiperglicêmico agudo em ratos diabéticos que ocorre provavelmente através de uma inibição da absorção intestinal da glicose ${ }^{15}$.

\section{Ação de hepatotoxicidade}

Não foi encontrado na literatura nenhum artigo descrevendo especificamente a hepatotoxicidade das duas espécies da sucupira. Porém, dois artigos relatam um surto de intoxicação e mortalidade de bovinos nos estados de Mato Grosso, Mato Grosso do Sul e Goiás por terem ingerido folhas da espécie $\mathrm{P}$ emarginatus ${ }^{16,17}$. Sugere-se que novas investigações precisam ser desenvolvidas para caracterizar se a presença das lesões encontradas nos animais tem relação realmente com o consumo da Pterodon emarginatus.

\section{Discussão}

A teoria das racionalidades médicas abriu um campo de conhecimento que permite estudar as relações entre distintos sistemas médicos e suas representações de corpo, saúde, doença e tratamento e a aplicabilidade das práticas integrativas ${ }^{18}$. Estas, por sua vez, possuem uma abordagem altamente subjetiva que considera outros fatores além do biológico, como emocional, social e energética, quando se busca validá-las por estudos clínicos randomizados esvazia-se toda sua lógica de fundamento e os resultados são oscilantes e discordantes.

Pesquisas em práticas integrativas na saúde exigem uma pluralidade científica que valide outros modos de saber, como, por exemplo, a pesquisa qualitativa que inclui a experiência subjetiva do indivíduo. O que condiz com a etnobotânica, que, segundo AMOROZO (1996) ${ }^{19}$, é o estudo do conhecimento e das conceituações desenvolvidas por qualquer sociedade a respeito do mundo vegetal, englobando tanto a maneira como o grupo social classifica as plantas, como os usos que dá a elas. Ela inclui todos os estudos relativos à relação entre populações tradicionais e as plantas ${ }^{20}$.

A etnobotânica recebeu destaque com o passar dos anos, e passou e passa cada vez mais a aumentar o interesse de pesquisadores sobre o assunto. Derivado de uma visão interdisciplinar permite agregar colaboradores de diferentes ciências, com enfoques diversos como o social, cultural da agricultura, da paisagem, da taxonomia popular, da conservação de recursos genéticos, da linguística e outros ${ }^{21}$.

A medicina popular em conjunto com a medicina vitalista enxerga o ser humano em sua relação com seus pares e seu meio buscando a promoção do equilíbrio dinâmico de sua energia vital, que varia de acordo com os sentimentos/pensamentos, as relações familiares e sociais e os comportamentos do indivíduo, estando embasados, por tanto, no chamado paradigma vitalista, que enxerga o corpo como uma totalidade bioenergética.

Tanto as racionalidades médicas quanto a medicina vitalista e o conceito de etnobotânica, tem ideias similares com o que a Naturologia agrega em sua filosofia. Assim como Adriana Elias Magno da Silva $(2012)^{22}$ descreve:

"A Naturologia é um conhecimento caracterizado pela mescla de racionalidades médicas, de filosofias e de técnicas de cura orientais e ocidentais, modernas e tradicionais. Apresenta-se como um conhecimento transdisciplinar filiado a modelos integrativos e complementares de atuação e atenção em saúde. Verificou se e como ocorre, na produção acadêmica brasileira de Naturologia, a incorporação dos princípios da transdisciplinaridade, da complexidade e da integralidade que 


\section{Brazilian Journal of Natural Sciences | Versão On-line ISSN 2595 - 0584 \\ Edição no 1- vol. 2 - maio 2018 | www.bjns.com.br}

a caracterizam. A análise da empírica confirmou a hipótese de que o saber e o fazer naturológico está ligado a princípios e paradigmas críticos do conhecimento com a transdisciplinaridade, complexidade e integralidade." (SILVA, 2012, p. 7)

O presente artigo, assim como a Naturologia, teve o intuito de promover a integralidade do cuidado e a pluralidade dos saberes, neste caso unindo conhecimento popular e o conhecimento científico na indicação de um fitoterápico. É relevante ressaltar a importância que as pesquisas científicas têm dentro do âmbito profissional, onde darão base a uma indicação terapêutica cautelosa $\mathrm{e}$ eficaz. Estes dois conhecimentos farão da postura profissional, mais completa, tendo como repertório o máximo de informação sobre a planta. $\mathrm{E}$ então unir os saberes dessas duas racionalidades médicas, a científica e a popular brasileira.

Este artigo teve como proposta analisar através do efeito biológico das duas espécies da sucupira, Bowdichia virgilioides e Pterodon emarginatus, se este tem relação com a descrição do uso da planta medicinal no contexto da medicina popular, por meio da revisão de artigos científicos que discorrem sobre as mesmas, resultando em uma comparação na qual, observou-se que as indicações na medicina popular têm uma ligação com os efeitos biológicos descobertos de pela ciência.

De acordo com FERREIRA et al $(2004)^{12}$, a população faz uso da casca da sucupira para tratar feridas, por ser anti-ulcerativa e anti-diabética. E isto pode ser visto no artigo de AGRA et al (2013) ${ }^{9}$, onde afirma depois de experimentos que a planta realmente tem efeito cicatricial, por conta do aumento da atividade dos fibroblastos. E ação hipoglicemiante pode ser esclarecida de acordo com a descrição de SILVA (2014) ${ }^{15}$ sobre sua ocorrência através de uma inibição da absorção intestinal da glicose.

CRUZ $(1965)^{4}$ diz que as sementes são utilizadas de forma popular no tratamento de reumatismo, artrite e doenças de pele. E a pesquisa de BARROS $(2010)^{7}$ vem de encontro dizendo que quer pela inibição da síntese, libertação ou a ação principalmente das prostaglandinas, as sementes de sucupira têm um efeito anti-inflamatório, por isso pode ajuda nas doenças citadas acima.

$\mathrm{O}$ efeito ansiolítico encontrado por VIEIRA et al $(2013)^{14}$ em seu artigo revela a ação do extrato aquoso da casca da B. virgilioides, mas os autores não foram a busca de qual dos componentes explicaria esta ação. Na medicina popular, a ação ansiolítica não foi relatada. No quadro 1 , observase os achados científicos relacionados à medicina popular.

Considera-se que seja de fundamental importância que os profissionais da área da saúde que indicam fitoterápicos tenham conhecimento da composição química e efeitos biológicos que cada planta medicinal possui. No entanto, sem perder também conhecimento vindo do próprio popular, que inclui a visão sobre a planta como um todo. Quando se equilibrar a pluralidade dos saberes populares e científicos, uma indicação muito mais abrangente, segura e eficaz poderá ser obtida com a indicação de plantas medicinais.

Diferentes efeitos foram encontrados nos artigos científicos, tais como efeito ansiolítico, anti-ulcerativo, leishmanicida e contra células cancerosas. Porém fica evidente a necessidade de mais estudos sobre tais ações, além de um estudo que abranja e evidencie a posologia adequada do uso da planta, juntamente com a possível toxicidade da sucupira.

\section{Conclusão}

Este presente artigo mostrou que a utilização da sucupira das espécies Bowdichia virgilioides e Pterodon emarginatus tem relação com a indicação terapêutica encontrada na medicina popular por meio da literatura bibliográfica. 


\begin{tabular}{|c|c|c|}
\hline Efeito Biológico & Medicina Popular & Artigos Científicos \\
\hline ação antinoceptiva & analgesia ${ }^{2}$ & $\begin{array}{c}\text { "O óxido de etileno pode atuar, pelo menos } \\
\text { parcialmente, na inibição da morte celular por } \\
\text { apoptose" }\end{array}$ \\
\hline ação antinflamatória & $\begin{array}{c}\text { reumatismo, artrite, faringite, amigdalite e } \\
\text { bronquite }{ }^{4} \\
\text { reumatismo e dores de garganta }{ }^{2}\end{array}$ & $\begin{array}{c}\text { "Ação antiinflamatória, quer pela inibição da } \\
\text { síntese, libertação ou a ação principalmente das } \\
\text { prostaglandinas (BARROS, 2010) }\end{array}$ \\
\hline ação cicatricial & cura de feridas e anti-ulcerativa ${ }^{3}$ & $\begin{array}{c}\text { "Cicatrização cutânea em ratos em nove dias, } \\
\text { decorrente de um possível aumento da atividade } \\
\text { de fibroblastos" }\end{array}$ \\
\hline ação antimicrobiana & doenças de pele ${ }^{4}$ & $\begin{array}{c}\text { "Apresentou atividade antimicrobiana contra } \\
\text { bactérias Gram-positivas esporuladas e } \\
\text { nãoesporuladas, Gram-negativas e contra fungo } \\
\text { C.albicans"11 } \\
\text { "Não possui atividade antimicrobiana contra S. } \\
\text { aureus, P. aeruginosa e } E \text {. coli. A amostra das } \\
\text { sementes testadas não apresentou as } \\
\text { substâncias químicas potencialmente ativas sobre } \\
\text { as linhagens analisadas"12 } \\
\text { "Inibiu o crescimento de uma única estirpe de } \\
\text { bactérias; entre todas as cepas de fungos } \\
\text { testados, apenas quatro foram sensíveis ao } \\
\text { óleo"10 } \\
\text { "Inibiu o crescimento de S. aureus ATCC } 25923 \text { e } \\
\text { as FH e FB apresentaram expressiva atividade in } \\
\text { vitro para L. amazonensis"13 }\end{array}$ \\
\hline ação leishmanicida & não relatada & $\begin{array}{c}\text { "Inibiu o crescimento de S. aureus ATCC } 25923 \text { e } \\
\text { as FH e FB apresentaram expressiva atividade in } \\
\text { vitro para L. amazonensis" }\end{array}$ \\
\hline ação hipoglicemiante & anti-diabético & "Inibição da absorção intestinal da glicose"15 \\
\hline ação ansiolítica & não relatada & "Tratamento de perturbações de ansiedade" 14 \\
\hline
\end{tabular}

Quadro 1: Efeitos biológicos encontrados na Medicina Popular e em Artigos Científicos sobre a sucupira das espécies Pterodon emarginatus e Bowdichia virgilioides. 


\section{Referências Bibliográficas}

1. OLIVEIRA DMT, PAIVA EAS - Anatomy and ontogeny of Pterodon marginatus (Fabaceae: Faboideae) seed. Braz J Biol. 2005, 65 (3): 483-494.

2. LORENZI H - Árvores brasileiras: manual de identificação e cultivo de plantas arbóreas nativas do Brasil. Nova Odessa: Plantarum, 2002. v.2, $368 \mathrm{p}$.

3. FERREIRA AR. Plantas medicinais usadas para tratamentos dermatológicos, em comunidades da Bacia do Alto Paraguai, Mato Grosso. Rev Bras Farmacogn. 2004, 14(Supl 1): 40-44.

4. CRUZ GL - Livro Verde das Plantas Medicinais e Industriais do Brasil. Belo Horizonte: Ed. Helmus, 1965.

5. GREENHALGH T. Papers that summarise other papers (systematic reviews and metaanalyses). BMJ. 1997, 315 (7109): 672-675.

6. HIGGINS JPT, GREEN S - Cochrane handbook for systematic reviews of interventions.Version 5.0.0. Cochrane Collaboration, 2008. Disponível em: http://training.cochrane.org/handbook.

7. BARROS WM. et al - Anti-inflammatory effect of the ethanolic extract from Bowdichia virgilioides H.B.K stem bark. An Acad Bras Ciênc. 2010, 82 (3): 609-616.

8. DUTRA RC et al - Chemical composition and cytotoxicity activity of the essential oil of Pterodon emarginatus. Rev bras farmacogn. 2012, 22 (5): 971-978

9. AGRA IKR et al - Evaluation of wound healing and antimicrobial properties of aqueous extract from Bowdichia virgilioides stem barks in mice. An Acad Bras Ciênc. 2013, 85 (3): 945-954.

10. ALMEIDA JRGS et al. - Antimicrobial activity of the essential oil of Bowdichia virgilioides Kunt. Rev bras farmacogn. 2006, 16 (suppl): 638641.

11. BUSTAMANTE KGL et al - Avaliação da atividade antimicrobiana do extrato etanólico bruto da casca da sucupira branca (Pterodon emarginatus Vogel) - Fabaceae. Rev bras plantas med. 2010, 12(3): 341-345.

12. FERREIRA SB, DANTAS IC, CATAO RMR

- Avaliação da atividade antimicrobiana do óleo essencial de sucupira (Pterodon emarginatus Vogel). Rev bras plantas med. 2014, 16 (2): 225-230.

13. DUTRA RC et al. - Atividades antimicrobiana e leishmanicida das sementes de Pterodon emarginatus Vogel Rev Bras Farmacogn. 2009, 19(2A): 429-435.

14. VIEIRA LFA et al - Anxiolytic-like effect of the extract from Bowdichia virgilioides in mice. Rev bras farmacogn. 2013, 23 (4): 680-686.

15. SILVA ACM et al - Acute and Subchronic Antihyperglycemic Activities of Bowdichia virgilioides Roots in Non Diabetic and Diabetic Rats. J Intercult Ethnopharmacol. 2015; 4(1): 57-63.

16. CRUZ RAS et al. - Intoxicação espontânea e experimental por Pterodon emarginatus (Fabaceae Faboideae) em bovinos e experimental em ovinos. Pesq Vet Bras. 2012, 32 (11): 1087-1094.

17. SANTANA FJF et al. Intoxicação espontânea por Pterodon emarginatus (Fabaceae) em bovinos no Estado de Goiás. Pesq Vet Bras. 2012, 32 (6):485-489.

18. LUZ MT - Racionalidades médicas e integralidade. Ciênc. saúde coletiva. 2008, 13 (1): 219.

19. AMOROZO MCM - A abordagem etnobotânica na pesquisa de Plantas Medicinais. In: DI STATSI, L.C. (Org.). Plantas medicinais: Arte e Ciência, um guia de estudo interdisciplinar. São Paulo: EDUSP. p. 47-68. 1996.

20. COTTON, C.M. Ethnobotany: principles and applications. New York: J. Wiley, 320p, 1996.

21. MING LC, HIDALGO AF, SILVA SMP - A Etnobotânica e a conservação de recursos genéticos. In: Albuquerque, U.P. (Org). Atualidades em Etnobiologia e Etnoecologia. Recife: SBEE, p.141$151,2002$.

22. SILVA AEM - Naturologia: Um diálogo entre saberes. 2012. 214 f. Tese (Doutorado em Ciências Sociais) - Pontifícia Universidade Católica de São Paulo, São Paulo. 2012. 